\title{
Neusilin based liquisolid compacts of albendazole: Design, development, characterization and in vitro anthelmintic activity
}

\author{
Amol SHETE 1 * (D) , Ashwini SALUNKHE 2 (D) , Adhikrao YADAV ${ }^{3}$ (D) , Sfurti SAKHARE ${ }^{3}$ (D) , \\ Rajendra DOIJAD ${ }^{1}$ (D)
}

1 Department of Pharmaceutics, Krishna Institute of Pharmacy of Krishna Institute of Medical Sciences “Deemed To Be University", Karad - 415110, India.

2 Research Group Department of pharmaceutics and Quality Assurance, Shree Santkrupa College of Pharmacy, Ghogaon, Karad - 415111, India.

3 Gourishankar Institute of Pharmaceutical Education and Research, Limb, Satara - 415002, India.

* Corresponding Author. E-mail: amol.shete@rediffmail.com (A.S.); Tel. +91 9822916129.

Received: 17 November 2018/ Revised: 06 February 2019 / Accepted: 07 February 2019

\begin{abstract}
The present investigation deals with enhancement of dissolution rate of high dose drug albendazole (ABZ) using liquisolid compacts. Study of precompression characteristics, influence of excipients on drug release characteristics and to compare drug release profile of the formulated liquisolid compacts with the directly compressible laboratory made formulation. Liquisolid compacts were prepared by using three by twofactorial designs and evaluated for differential scanning calorimetry (DSC), powder X-ray diffraction (PXRD), in vitro nthelmintic, in vitro antifungal study and in vitro dissolution study. There was improvement in the dissolution rate and solubility was attributed to decreased melting point and crystallinity of albendazole. In vitro anthelmintic and antifungal activities of neusilin based liquisolid compacts were more than pure albendazole. The drug content of liquisolid compacts was not affected when stored at room temperature for a period of 3 months. This study also provided evidence that it is possible to load high amounts of drug into liquisolid compacts due to the neusilin allows higher liquid adsorption capacities. Neusilin based technique is useful for the preparation of liquisolid compacts of high dose drug like albendazole with enhancement in dissolution rate
\end{abstract}

KEYWORDS: Albendazole; dissolution; liquisolid; compacts.

\section{INTRODUCTION}

There are various routes of administration has been evaluated for new drug entities, the most popular remains the oral route due to the greater flexibility in design and high patient compliance. Because of greater stability, accuracy in dose, easy of production, formulation in the form of tablets is the preferred oral dosage form [1]. The drug must be presents in solution form for absorption through gastrointestinal tract (GIT) when given orally. In the case of poorly soluble drugs, dissolution is the rate-limiting step in absorption process. Generally, compounds with aqueous solubility less than $100 \mu \mathrm{g} / \mathrm{mL}$ shows dissolution rate limited absorption and erratic and/or incomplete absorption from the gastrointestinal tract of animals and humans [2].

Different methods are employed to improve the dissolution characteristics of poorly water soluble drugs including various formulation approaches to enhance solubility of drugs e.g. use of solvent mixtures, cyclodextrins, particle engineering and lipid based approaches. The principle limitation of all these approaches is that the drug needs to possess certain physicochemical properties or to 'fit' to the solubilizing principle (e.g. having the right molecular size to fit into the cyclodextrin ring). For many decades by reducing the particle size to increase the dissolution rate of poorly water-soluble drugs is the most popular practice. Micronization of sparingly or poorly soluble drugs is by no means a guarantee of better dissolution and absorption. A hydrophobic powder with small particle size leads to aggregation, making it difficult to disperse. The particles float on the dissolution medium because of entrapped air. It is difficult to remove or wet these particles. All these effects, in fact, reduce the rate of dissolution consequently; the next step was taken to move from

How to cite this article: Shete A, Salunkhe A, Yadav A, Sakhare S, Doijad R. Neusilin based liquisolid compacts of albendazole: Design, development, characterization and in vitro anthelmintic activity. J Res Pharm. 2019; 23(3): 441-456. 
micronization to nanonisation that means producing drug nanocrystals. By definition drug nanocrystals are nanoparticles being composed of $100 \%$ drug without any matrix material, according to the definition of nanoparticles the mean particle size is below $1 \mathrm{~mm}$ (i.e. in the nanometer range, typically somewhere between 200 and $500 \mathrm{~nm}$ ). Typically, the drug nanocrystals were generated in a liquid dispersion medium (e.g. by precipitation or a disintegration process). The obtained product from this process is a suspension of drug nanocrystals in a liquid stabilized by a surfactant or polymer (so-called 'Nanosuspension'). In contrast to micronized powders the drug nanocrystals can be administered using very different administration routes. In addition, because of their small size the Nanosuspension can be injected parenterally, especially intravenously. Intravenous injection leads 'per definition' to a $100 \%$ bioavailability, but this technology is too economic. In generic development cost of formulation will be high [3].

Liquisolid means formulation where, conversion of liquid drugs, drug suspensions or drug solution in nonvolatile solvents into dry, non-adherent, free-flowing and compressible powder mixtures by blending the suspension or solution with selected carriers and coating materials. It may enhance the wetting properties and surface area of drug available for dissolution, liquisolid compacts of water-insoluble substances may be expected to display enhanced drug release characteristics and consequently, improve oral bioavailability. Since dissolution of a non-polar drug is often the rate limiting step in gastrointestinal absorption, better bioavailability of an orally administered water-insoluble drug is achieved when the drug is already in solution, thereby displaying enhanced dissolution rates. That is soft gelatin elastic capsules containing solutions of such medications demonstrate higher bioavailability when compared to conventional oral solid dosage forms. A similar principle underlies the mechanism of drug delivery from liquisolid compacts [3].

This technique was successfully applied for low dose water-insoluble drugs. However, formulation of the high dose insoluble-drugs as liquisolid compacts is one of the limitations of the liquisolid technique [5]. Desired dose of drug more than $100 \mathrm{mg}$ in order to have acceptable flowability and compactability for liquisolid powder formulation requirement of large amount of carrier and coating material results in unacceptably increase in tablet weight over $1 \mathrm{gm}$ which is difficult for the patient to swallow. There is need to overcome this limitation by replacement of the commonly used carrier materials by the highly adsorptive novel carrier materials such as neusilin, which results in a reduction of the tablet weight and it would be possible to produce dry powder formulations containing liquid with high concentration of drug. The novelty in present investigation is formulated $200 \mathrm{mg}$ of albendazole with neusilinUS2. Neusilin US2 is a fine ultralight granule of magnesium aluminometasilicate and is widely accepted as a multifunctional excipient that improves the quality of pharmaceuticals [4-5]. The drugs formulated as liquisolid compacts with neusilin are carbamazepine, progesterone, meloxicam etc. [4]

Albendazole (ABZ), methyl [5-(propylthio)-1-H-benzimidazol-2yl] carbamate, is undoubtedly the most effective of the broad-spectrum anthelmintic agents, good tolerance and low cost [6] The albendazole therapy is very important in systemic cestode infections especially in inoperable or disseminated cases of hydatidosis and neurocysticercosis [7].

Literature reports inclusion complex and nanoclusters of cyclodextrin, albendazoledesmotropes by supramolecularsystems with maltodextrin and glutamic acid, spray drying with lactose and other water soluble excipients, microcrystals using gum karaya and hupu gum as stabilizing agents and microcrystals with chitosan and cellulose derivatives are reported for enhancement of solubility, dissolution rate and indirectly bioavailability of albendazole [8-14]

The low cost and broad spectrum of activity of ABZ make it typically the drug of choice for these cases. However, it's very low solubility results in low absorption through the gastrointestinal tract and in some applications, such as for the systemic diseases, high oral doses that cause adverse gastrointestinal disturbances and several detrimental side effects occur [15]. This property is a major disadvantage for the use of ABZ in the treatment of systemic helminthiasis. Furthermore, the lack of water solubility reduces flexibility for ABZ formulation and administration. Therefore, the overcome of poor aqueous solubility of ABZ is important and needed. The objectives of present investigation were to prepare a liquisolid compact of high dose drug albendazole by using neusilin US- 2 as a carrier material.

\section{RESULTS AND DISCUSSION}

\subsection{Solubility analysis of albendazole and flowable liquid retention potential ( $\Phi$ - Value)}

The solubility of the drug was investigated in different solvents like propylene glycol, polyethylene glycol 400. The highest solubility of drug was found with polyethylene glycol 400 and chosen as non-volatile 
liquid vehicle for formulation of liquisolid compacts of ABZ. Table 1 and 2 shows saturation solubility data for the albendazole in various solvents and flowable liquid retention potential.

Table 1. Saturation solubility data for the Albendazole in various solvent.

\begin{tabular}{cc}
\hline Solvent & Solubility $(\mathbf{m g} / \mathbf{m l})$ \\
\hline Propylene glycol & $21.32 \pm 0.02$ \\
Glycerine & $10.12 \pm 0.07$ \\
PEG 200 & $42.64 \pm 0.21$ \\
Tween 20 & $32.45 \pm 0.08$ \\
Tween 80 & $35.74 \pm 0.30$ \\
PEG 400 & $47.22 \pm 0.22$ \\
\hline
\end{tabular}

Table 2. Flowable Liquid retention potential value of various excipients ( $\Phi$ - value).

\begin{tabular}{ccc}
\hline Sr.No. & Excipient & $\boldsymbol{\Phi}$ - Value \\
\hline $\mathbf{1}$ & Neusilin US2 & 1.45 \\
$\mathbf{2}$ & Aerosil 200 & 2.5 \\
\hline
\end{tabular}

\subsection{Liquid load factor}

Using "new formulations mathematical model", the straight line equation for neusilinUS2 and Aerosil 200 in PEG 400 will be:

$$
\mathrm{Lf}=1.45+2.5(1 / \mathrm{R})
$$

For each $\mathrm{R}$ value used, the corresponding Lf value can be calculated as given in Table 3 . As soon as the optimum liquid load factor Lf of a given excipients ratio is established for each formula and $\mathrm{W}$ of liquid medication is calculated according to Albendazole concentration in PEG 400, the appropriate quantities of neusilin US2 (Qo) and Aerosil 200 (qo) required to convert a given amount of liquid medication (W) into an acceptably flowing and compressible liquisolid system. The optimum quantity of carrier and coating material can be calculated by following equations and shown in Figure 1.

$$
\begin{aligned}
& \text { Qo }=W / L o \\
& q o=Q o / R
\end{aligned}
$$

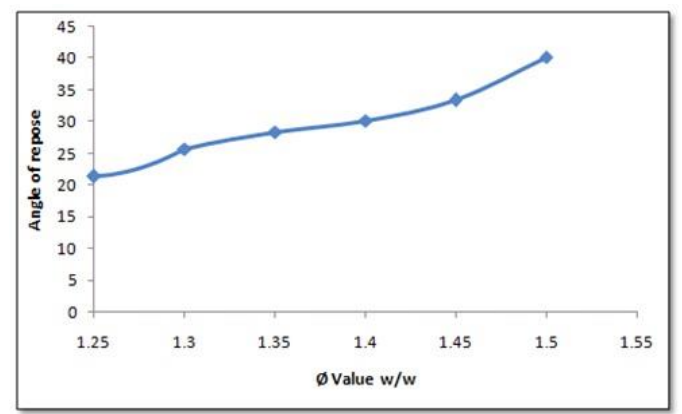

Figure 1. Relationship between the angle of repose $\theta$ and $\Phi$ - value for neusilin US2.

Table 3. Different $L_{F}$ values for different ratios of carrier and coating material.

\begin{tabular}{ccc}
\hline Sr. No & $\begin{array}{c}\text { Carrier to Coating material } \\
\text { ratio (R) }\end{array}$ & $\begin{array}{c}\text { Liquid load factor of neusilin US2 with } \\
\text { Aerosil 200 }\end{array}$ \\
\hline $\mathbf{1 .}$ & 15 & 1.61 \\
$\mathbf{2}$. & 20 & 1.57 \\
$\mathbf{3}$ & 25 & 1.55 \\
\hline
\end{tabular}

\subsection{Flow properties of the albendazole liquisolid system}

Flowability improvement attributed to the sponge like liquid uptake into these porous excipient resulting weight gains of individual particles. Therefore, different flow parameters were employed such as, the angle of repose $(\theta)$, Carr's compressibility index and Hausner's ratio and their results are presented in 
(Table 4). This shows good flow properties with $\theta$ values 34 and considered as liquisolid system with acceptable flowability and liquisolid system with higher $\theta$ values are considered non acceptable.

Carr's index up to 16 was considered of acceptable flow properties. In addition to Carr's index, Hausner's ratio is related with the inter particle friction, so, that powders with low interparticle friction, had ratios of approximately 1.25 indicating good flow. Regarding LS- 1 to LS-9 formulations, neusilin was used as carrier to adsorb excessive liquid, whereas excess neusilin may act as a glidant to improve powder flowability their results are presented in (Table 4). Overall, it was observed that liquisolid formulations prepared from liquid medications with higher drug concentration $(\% \mathrm{w} / \mathrm{w})$ showed better flow and compactibility compared to those prepared from liquid medications with lower drug concentration $(w / w)$ of the same liquid vehicle.

Table 4. Flow Parameters of neusilin based ABZ liquisolid system.

\begin{tabular}{cccc}
\hline $\begin{array}{c}\text { Liquisolid } \\
\text { System }\end{array}$ & Angle of Repose $\left(^{\mathbf{0}}\right)$ & Carr's Index (\%) & Hausner's Ratio \\
\hline LS 1 & $35.43 \pm 0.31$ & $20.24 \pm 0.17$ & $1.37 \pm 0.03$ \\
LS 2 & $27.61 \pm 0.34$ & $14.66 \pm 0.67$ & $1.26 \pm 0.02$ \\
LS 3 & $31.38 \pm 1.01$ & $17.39 \pm 0.42$ & $1.34 \pm 0.03$ \\
LS 4 & $33.86 \pm 0.88$ & $19.63 \pm 0.31$ & $1.33 \pm 0.02$ \\
LS 5 & $25.26 \pm 0.62$ & $13.47 \pm 0.26$ & $1.23 \pm 0.01$ \\
LS 6 & $32.33 \pm 0.78$ & $18.46 \pm 0.35$ & $1.26 \pm 0.02$ \\
LS 7 & $36.24 \pm 0.59$ & $17.04 \pm 0.63$ & $1.27 \pm 0.02$ \\
LS 8 & $26.21 \pm 0.78$ & $14.79 \pm 0.69$ & $1.24 \pm 0.01$ \\
LS 9 & $33.67 \pm 0.51$ & $15.46 \pm 0.29$ & $1.24 \pm 0.05$ \\
\hline
\end{tabular}

All values expressed as \pm mean standard deviations.

\subsection{Post -compression studies of liquisolid compacts}

The thickness of the tablet was determined by the diameter of die, the amount of fill permitted to enter the die, the compaction characteristic of the fill material and the force applied during compression.

The variations in tablet thickness for the prepared batches due to the different tablet weights .In neusilin based liquisolid tablets requirement of carrier and coating material was less due to neusilin having high specific surface area and require low compression force due to superior compressibility of neusilin. These results are presented in Table 5 and 6.

Table 5. Results of the quality control tests performed on neusilin based compacts ABZ liquisolid compact.

\begin{tabular}{|c|c|c|c|c|}
\hline Formulation & $\begin{array}{c}\text { Diameter } \\
(\mathrm{mm})\end{array}$ & Thickness (mm) & $\begin{array}{l}\text { Hardness } \\
\left(\mathrm{Kg} / \mathrm{cm}^{2}\right)\end{array}$ & Wt. Variation (\%) \\
\hline LS 1 & $13.09 \pm 0.03$ & $2.9 \pm 0.06$ & $3.43 \pm 0.20$ & $1 . .243 \pm 0.06$ \\
\hline LS 2 & $13.08 \pm 0.10$ & $2.84 \pm 0.02$ & $4.4 \pm 0.20$ & $1.234 \pm 0.21$ \\
\hline LS 3 & $13.06 \pm 0.01$ & $2.56 \pm 0.02$ & $4.26 \pm 0.30$ & $1.453 \pm 0.30$ \\
\hline LS 4 & $13.03 \pm 0.02$ & $3.36 \pm 0.08$ & $3.53 \pm 0.70$ & $1.234 \pm 0.06$ \\
\hline LS 5 & $13.10 \pm 0.01$ & $3.04 \pm 0.03$ & $4.26 \pm 0.15$ & $1.521 \pm 0.02$ \\
\hline LS 6 & $13.15 \pm 0.01$ & $2.63 \pm 0.04$ & $4.26 \pm 0.30$ & $1.432 \pm 0.02$ \\
\hline LS 7 & $13.13 \pm 0.01$ & $2.58 \pm 0.04$ & $3.46 \pm 0.23$ & $1.342 \pm 0.06$ \\
\hline LS 8 & $13.08 \pm 0.04$ & $2.74 \pm 0.08$ & $4.36 \pm 0.15$ & $1.231 \pm 0.17$ \\
\hline LS 9 & $13.1 \pm 0.03$ & $2.56 \pm 0.10$ & $4.53 \pm 0.30$ & $1.213 \pm 0.31$ \\
\hline
\end{tabular}


Table 6. Results of the quality control tests performed on neusilin based compacts ABZ liquisolid compact.

\begin{tabular}{cccc}
\hline Formulation & Content Uniformity (\%) & Friability (\%) & Disintegration Time (Sec) \\
\hline LS 1 & $101.12 \pm 0.05$ & $0.42 \pm 0.03$ & $240.66 \pm 0.57$ \\
LS 2 & $97.12 \pm 0.01$ & $0.54 \pm 0.03$ & $231.33 \pm 1.57$ \\
LS 3 & $93.55 \pm 0.02$ & $0.62 \pm 0.01$ & $220.66 \pm 1.15$ \\
LS 4 & $102.06 \pm 0.05$ & $0.46 \pm 0.02$ & $246.66 \pm 0.57$ \\
LS 5 & $95.83 \pm 0.05$ & $0.59 \pm 0.03$ & $235.66 \pm 1.15$ \\
LS 6 & $92.58 \pm 0.31$ & $0.65 \pm 0.02$ & $222.66 \pm 1.52$ \\
LS 7 & $101.56 \pm 0.27$ & $0.46 \pm 0.02$ & $240.66 \pm 1.15$ \\
LS 8 & $99.55 \pm 0.24$ & $0.56 \pm 0.04$ & $242.33 \pm 1.52$ \\
LS 9 & $93.53 \pm 0.30$ & $0.66 \pm 0.01$ & $226.66 \pm 0.57$ \\
\hline
\end{tabular}

*All values expressed as Mean \pm standard deviation

Hardness of liquisolid compacts ranged from $3.43 \pm 0.20-4.4 \pm 0.20$. It was observed that as the amount of neusilin increases, hardness also increases. With decrease in $\mathrm{R}$ values, hardness also decreased. This low hardness could be attributed to the less amount of added neusilin and poor compressibility of Aerosil. The hydrogen bonds between hydrogen groups on adjacent molecules neusilin may account almost exclusively for the strength and cohesiveness of compacts .The high compressibility and compactness of neusilin can be explained by the nature of the neusilin particles themselves which are held together by hydrogen bonds, when compressed, such particles are deformed plastically and a strong compact is formed due to the extremely large number of surfaces brought in contact during the plastic deformation and the strength of the hydrogen bonds formed. Tablets with low hardness were not considered because they were not able to withstand abrasion in handling. Neusilin possess high amount of silanol group's i.e. Si-OH. Therefore, neusilin makes hard tablets at low compression force and in addition, at low concentrations can improve the hardness of other filler and binder excipients. Weight variation test revealed that the tablets were within the range of Pharmacopoeial specifications. All the formulations passes weight variation test.

All the liquisolid compacts had acceptable friability as none of the tested formulae had percentage loss in tablet's weights that exceed 1\%. Friability below $1 \%$ is an indication of good mechanical resistance of the tablets. This ensures that tablets could withstand to the pressure, shocks during handling, transportation and manufacturing processes.

In liquisolid $\mathrm{N}$ compacts thus, drug release was not hindered by slow disintegration of the dosage form. Tablets containing neusilin (LS-N) disintegrated within $246.66 \pm 0.57 \mathrm{sec}$ because of the poor disintegration properties of this silicate [16]. In addition, use of Cross carmellose sodium acts by facilitating water uptake into tablet pore, rapid swelling causing increase pressure in the tablet pore and ultimately breakdown of tablets [17].

As shown in table 6drug content uniformity were observed for liquisolid $\mathrm{N}$ compacts ranged from $92.58 \pm 0.31 \%-101.56 \pm 0.07 \%$.The higher amount of carrier materials used in liquisolid formulations leads to more uniform drug distribution due to increased surface area for adsorption or absorption of liquid medication onto or into the carrier, thereby leading to homogeneous distribution of the active ingredient within the batch. This is consistent with our findings whereby liquisolid formulations that complied with IP content uniformity specifications [17-18].

\subsection{Differential scanning colorimetry}

DSC is one of the most common applications to determine and predict the physicochemical interaction between components in a formulation. The thermogram of pure albendazole (Figure 2a) showed a sharp endothermic peak at $208.86^{\circ} \mathrm{C}$ due to drug melting. The sharp endothermic peak indicates that the albendazole was in crystalline state. Thermogram of neusilin based liquisolid formulations (Figure $2 \mathrm{~b}$ ) displayed very broad peaks. DSC thermograms of liquisolid formulation revealed a peak at $180.83^{\circ} \mathrm{C}$ that was markedly broadened, the intensity was reduced and the characteristic melting peak of albendazole was completely disappeared. This is an indicative of complete solubilisation of albendazole. The broad peak in the DSC profiles of liquisolid formulation might be corresponded to the melting and decomposition of the whole liquisolid system. The melting point of a substance is closely related to its solubility via latent heat of fusion, which is the amount of heat generated during melting or fusion. 


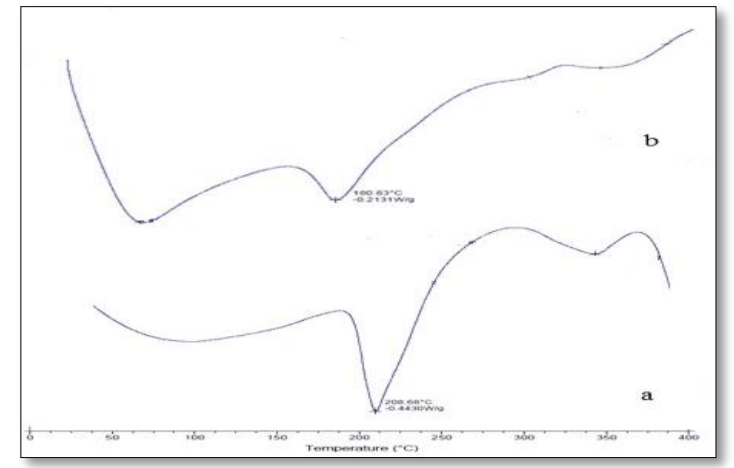

Figure 2. DSC thermogram of (a) pure albendazole; (b) Neusilin based ABZ liquisolid compact.

Generally, crystal with weak bonds has a low-melting point and low heat of fusion. On the contrary, crystal with strong bonds gives high melting point and high heat of fusion. The structure of drug crystal has to be disrupted in order to disperse or solubilize in a solvent. Accordingly, high melting point usually reflects low solubility [18-19].

\subsection{X-Ray powder diffraction (P-XRD)}

The x-ray diffraction pattern of pure drug (Figure 3a) exhibited sharp, highly intense and less diffused peaks indicating the crystalline nature of drugs at $2 \theta$ diffraction angles of $47.15,38.98,32.15$, and 22.12. An $x-$ ray diffraction peaks at $2 \theta$ diffraction angle of neusilin based liquisolid formulations (Figure 3b). 34.16.26.13, 18.98.The peaks remained unchanged but their relative intensity of peaks were decreased which might be due to the dilution of drug and crystallinity were decreased. Thus the reduced crystallinity were due to the LS contributes the improvement in dissolution rate. Decrease of crystallinity in the formulation might be due to solubilization of the drug, which was absorbed into the carrier and coating materials, in the liquid vehicle. These results agree with DSC results, suggesting formation of a solid solution of albendazole within PEG 400 (the carrier material). This phenomenon might be responsible for enhancement dissolution rate of albendazole $[18,20]$.

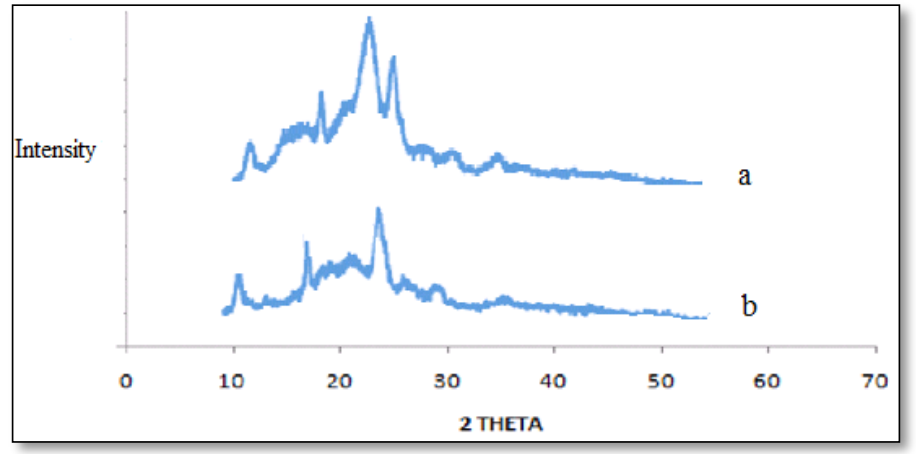

Figure 3. X-ray diffractogram of a. pure albendazole. b. Neusilin based ABZ liquisolid compacts.

\subsection{Factorial design with surface plot \& optimization of process variables}

From the data of \% drug released of the neusilin based liquisolid formulations LS 1 to LS 9, polynomial equation for \% drug release has been derived using 'PCP Disso 2000 V3 software'. The main effects (X1 and $\mathrm{X} 2$ ) represent the average results of changing one factor at a time from its low to high value. The interaction term (X1X2) shows how the response changes when two factors are simultaneously changed.

The equation derived for \% drug release of the factorial formulations is shown below:

$$
\text { Neusilin Based LS } \quad Y=97.85-4.4050 \text { X1 - 2.0133X2 - 7.3117 X1X2 }
$$

The negative sign for coefficients of $\mathrm{X} 1$ and $\mathrm{X} 2$ indicate that as the drug concentration in liquid medication and excipient ratio increases, \% drug release decreased. The results of a $3^{2}$ full factorial design revealed that the amount of drug concentration and carrier: coating material significantly affects the depended variable i.e \% drug released (Table 7). 
Table 7. $3^{2}$ full factorial design layouts of neusilin based liquisolid formulation.

\begin{tabular}{cccc}
\hline Batch Code & \multicolumn{2}{c}{ Variable levels in coded form } & $\begin{array}{c}\text { Drug released (\%) N } \\
\text { based LS }\end{array}$ \\
\cline { 2 - 3 } $\mathbf{1}$ & $\mathrm{x} 1$ & -1 & 97.94 \\
$\mathbf{n}$ & -1 & 0 & 94.49 \\
$\mathbf{3}$ & -1 & +1 & 92.41 \\
$\mathbf{4}$ & -1 & -1 & 99.41 \\
$\mathbf{5}$ & 0 & 0 & 98.62 \\
$\mathbf{6}$ & 0 & +1 & 95.53 \\
$\mathbf{7}$ & 0 & -1 & 87.60 \\
$\mathbf{8}$ & +1 & 0 & 85.88 \\
$\mathbf{9}$ & +1 & +1 & 84.93 \\
\hline
\end{tabular}

The significance level of coefficient of LS neusilin are b0, b1,b2 and b12 Were found to be 97.8533,4.4050,-2.0133 and -7.3117 respectively; hence, it was omitted from the full model to generate the reduced model.

The results of multiple regression analysis are shown in Table 8 . The coefficients b1, b2, and b12 were found to be significant at $a<0.05$. The results for testing the model in portions are shown in (Table 7). The critical value of $\mathrm{F}$ for $\mathrm{a}=0.05$ was equal to $123.05(\mathrm{DF}=5)$ for $\mathrm{LS}$ neusilin. It may be concluded that the interaction term and polynomial terms contribute significantly to the prediction of \% drug Released. Hence, conclusions can be drawn considering the magnitude of the coefficient and the mathematical sign (positive or negative) it carries, an increase in the drug concentration and excipient ratio leads to an decrease in \% drug released, because the coefficient $b 1, b 2$ and b12 bears a negative sign [21].

The data clearly showed that the \% drug release values are strongly dependent on the selected independent variables. The fitted equations (full and reduced) relating the response $\%$ drug release to the transformed factor is shown in (Table 8). The polynomial equations can be used to draw conclusions after considering the magnitude of coefficient and the mathematical sign it carries (i.e., positive or negative).The high values of correlation coefficient for \% drug release indicate a good fit. The equation may be used to get estimates of the response as a small error of variance was noticed in the replicates. The significance test for regression coefficients was performed by applying the $t$ test. A coefficient is significant if the calculated $t$ value is greater than the critical value of $t$ (25) by adopting a systematic formulation approach, an optimum point can be reached in the shortest time with minimum efforts.

A response surface plot allows visual observation of the significance of the regression equations by graphically depicting maxima and minima. The regression equation was presented in the form of a response surface plot in (Figure 4) shows the influence of independent variables X1 and X2 on the responses Y. As it can be seen from the plot, drug concentration in liquid vehicle (x1) and excipient ratio (X2) had significant effect on the $\%$ drug release from the liquisolid compact formulation. Decrease in $\%$ drug release was due to the general agreed observation that increase in drug concentration in liquid vehicle $50-55 \% \mathrm{w} / \mathrm{w}$ cause insufficient wetting of the drug particles and not increase aqueous solubility. Hence, \% Drug released will decrease with the increased drug concentration in liquid vehicle. Concentration of excipient ratio (X2) increase from 20-25 cause oversaturation of drug in silica pores had a negative impact on the \% drug release of liquisolid compact formulations [22].

Analysis of contour plot, shown in (Figure 5) reveals that the whole of the contour area has acceptable $\%$ drug Release values LS N (84.95-98.12). It were arbitrarily decided to select a batches LS N that dissolution rate more than $95 \%$.The final selection is done after considering other aspects such as ease of manufacturing, cost, etc. In industry, the total time required for manufacturing a dosage form is of prime concern [23]. 
Table 8. Multiple regression analysis for $3^{2}$ Factorial design of neusilin based liquisolid compacts.
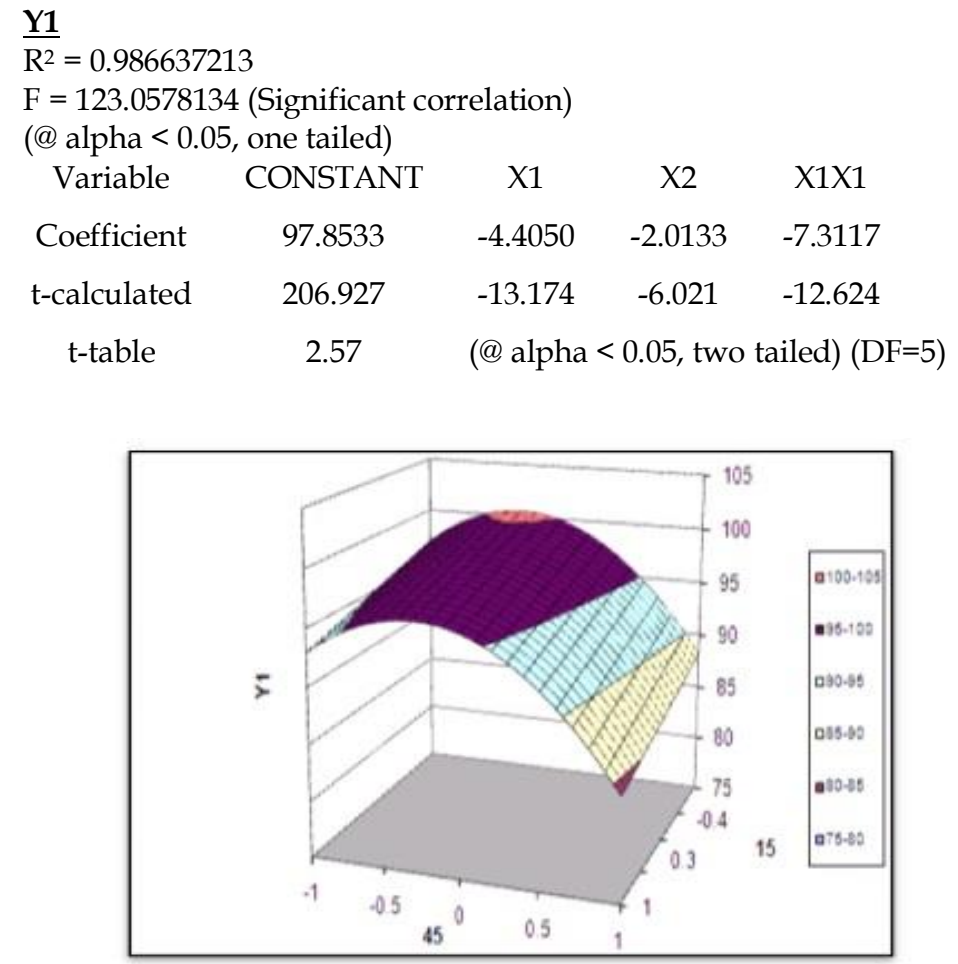

Figure 4. Response surface plot N LS showing effect of factorial variables on \% drug release. The shaded regions indicate the range of response variables, $\mathrm{Y}_{1}$ (\% drug release).

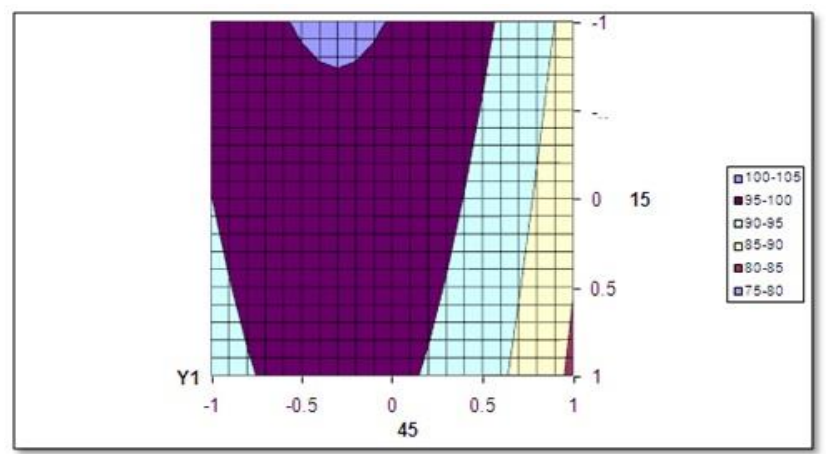

Figure 5. Contour plot showing effect of factorial variables on \% drug release from neusilin LS the shaded regions indicate the range of response variables, $\mathrm{Y}_{1}$ (\% Drug release).

\subsection{In vitro dissolution studies}

Albendazole was more soluble in PEG 400. The drug having higher the solubility, the more the drug particles dissolved in the liquid vehicles prior to the absorption onto the carrier materials. The solubility of a drug in the solvents is affected by different physicochemical properties of the solvents, such as hydrophilicity, polarity, viscosity, chemical structure and molecular weight, to different extents. PEG 400 possesses hydrophilic-lipophilic balance (HLB) values of 12. The higher HLB values indicate hydrophilic or polar properties, whereas low HLB values suggest lipophilic or non-polar characteristics. The dissolution profiles of albendazole liquisolid tablets and conventional tablets in 0.1N HCL shown in (Figure 6). The percentage of albendazole released from liquisolid formulation shows LS-1, LS-2, LS-3, LS-4, LS-5,LS-6,LS-7,LS-8 and LS-9 in $0.1 \mathrm{~N} \mathrm{HCL}$ at $60 \mathrm{~min}$ were 97.94, 94.49, 92.41,99.41,98.62,95.53,87.60,85.88 and 84.93 as shown in Figure 6.

The drug particles in liquisolid formulations were dispersed in selected hydrophilic liquid vehicle, which means the wetting properties of the drug particles were increased; hence, the surface area of drug particles available for dissolution increased tremendously. After liquisolid tablet was disintegrated, the primary particles of liquisolid suspended in the dissolution medium contained drug particles in a state of 
molecular dispersion. For conventional tablet, the surface exposed for dissolution was very limited, due to the hydrophobicity of the drug particles. Accordingly, the higher dissolution rates observed in liquisolid formulations may be attributed to significantly larger surface area of the molecularly dispersed drug particles. Since the drug particles in liquisolid formulations are in a state of molecular dispersion, its saturation solubility (Cs) might be increased. The small amount of liquid vehicle in a liquisolid tablet might not be adequate to increase the overall saturation solubility of drug particles in the dissolution medium. Nevertheless, in the diffusion layer (the solid/liquid interface between primary liquisolid particles and dissolution medium), in such a micro-environment, it is possible that infinite amounts of liquid vehicle diffuse with the drug particles away from the primary liquisolid particles. In this case, small amount of liquid vehicle might be sufficient to improve the solubility of drug particles by acting as a cosolvent with the dissolution medium of the diffusion layer. As a consequence of increase in Cs, the concentration gradient (Cs - C) of the drug will be increased, and hence, the drug dissolution rate will be increased [18].

The dissolution profiles of albendazole from liquisolid tablets with PEG 400 produced higher drug dissolution rate in comparison with the conventional tablets (DCT) in $0.1 \mathrm{~N} \mathrm{HCL}$ dissolution media.

Albendazole is a weak base $(\mathrm{pKa}=11)$ which displays $\mathrm{pH}$-dependent solubility and dissolution. The weak bases react with acids in $0.1 \mathrm{~N} \mathrm{HCL}$ and then exist as ions that are ordinarily soluble in water. In the other words, the concentration of the drug is high when the drug is mostly ionized. The dissolutions of liquisolid formulation were equally good in the $0.1 \mathrm{~N} \mathrm{HCL}$. Therefore, albendazole will not precipitate on the gastric mucosa and will not cause local irritation, but it is ready to dissolve in the gastric fluid and available for absorption [18]

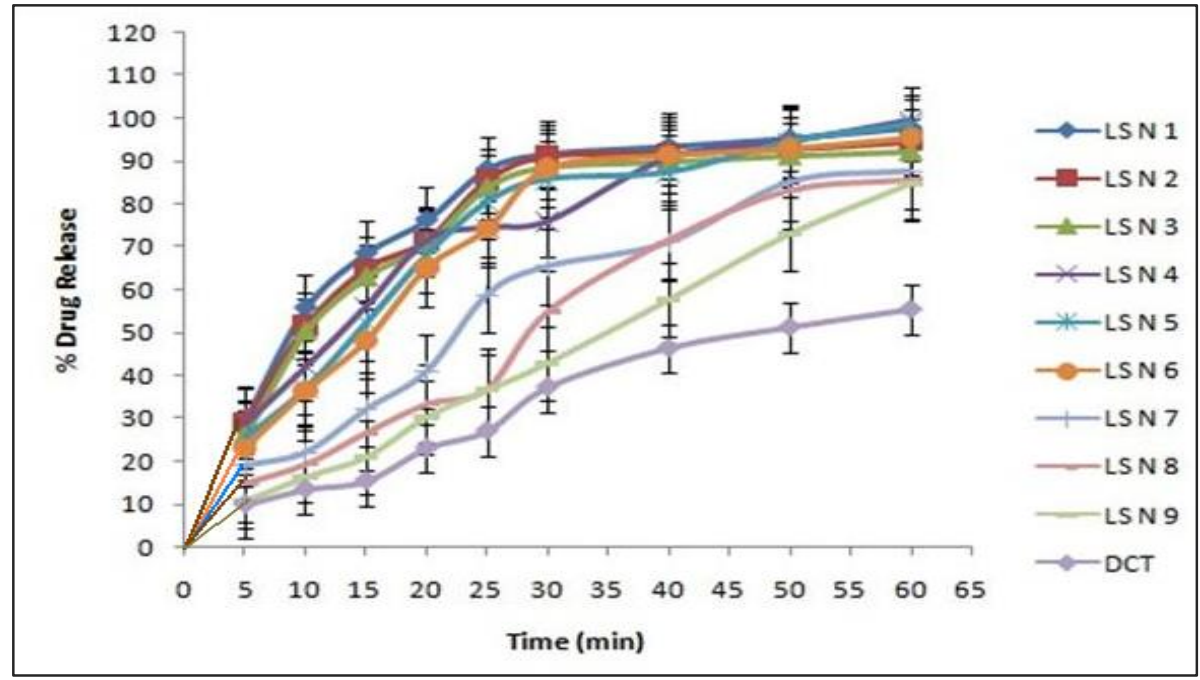

Figure 6. In vitro \% drug released from $\mathrm{N}$ based liquisolid compact and laboratory made tablet (DCT).

\subsection{In vitro anthelmintic activity of $\mathrm{ABZ}$ and $\mathrm{LS} \mathrm{N}$ liquisolid formulation}

Helminthes or worm infestations continue to be one of the most prevalent diseases and serious public health problems worldwide. The major control strategy adopted against helminthes or worm parasites has been the use of anthelminthic. Anthelmintic are the drugs used to eradicate or reduce the number of helminthic or worm parasites in the intestinal tract or tissues of human and other animals.

The result of anthelmintic activity exhibited by formulation on Pheretima Posthumaas shown in Table 9 and Figure 7. A closer inspection of data from this table indicates that $\mathrm{N}$ based liquisolid compacts showed more activity than albendazole. Albendazole liquisolid formulations by increasing chloride ion conductance of worm muscle membrane produces hyperpolarization and reduced excitability that leads to muscle relaxation and flaccid paralysis [24]. Albendazole liquisolid formulations cause paralysis in worm by disrupting the microfilaments, microtubules and $\beta$-tubulins component of their cytoskeletal structure.

Another possible suggestion for the observed paralysis and death of the worms is the binding of the albendazole liquisolid formulations to glycoproteins on the cuticle of the worms causing disruption of cell membrane integrity. Earlier researchers reported that anthelmintic agents act by binding to the free proteins in the gastrointestinal tract of the host animal or glycoproteins on the cuticle thereby causing disruption of cell membrane integrity, disruption of the metabolic pathways of the worms [24]. 


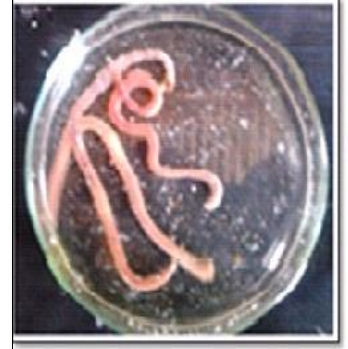

a. Control Earthworm in 2\%w/w Tween with Normal saline

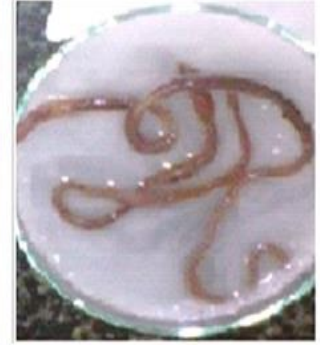

b. $A B Z 20 \mathrm{mg} / \mathrm{ml}=65 \mathrm{~min}$

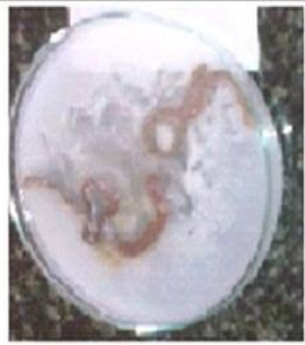

c.LS N $20 \mathrm{mg} / \mathrm{ml}=21 \mathrm{~min}$

Figure 7. Anthelmintic activity of a Control earthworm in $2 \% \mathrm{w} / \mathrm{v}$ tween with normal saline, $\mathbf{b}$ BZ and c.LS $\mathrm{N}$ formulation at the concentration $20 \mathrm{mg} / \mathrm{ml}$ against Indian Earthworm.

Table 9. Anthelmintic activity of albendazole and neusilin based liquisolid formulations against Indian Earthworm.

\begin{tabular}{|c|c|c|c|c|c|c|}
\hline \multicolumn{7}{|c|}{ Time taken for paralysis (P) and death (D) } \\
\hline \multirow[t]{2}{*}{ Test Compound } & \multicolumn{3}{|c|}{ Paralysis time (min) } & \multicolumn{3}{|c|}{ Death time (min) } \\
\hline & $5 \mathrm{mg} / \mathrm{ml}$ & $10 \mathrm{mg} / \mathrm{ml}$ & $20 \mathrm{mg} / \mathrm{ml}$ & $5 \mathrm{mg} / \mathrm{ml}$ & $10 \mathrm{mg} / \mathrm{ml}$ & $20 \mathrm{mg} / \mathrm{ml}$ \\
\hline Control & - & - & - & - & - & - \\
\hline LS N & 43 & 31 & 18 & 47 & 34 & 21 \\
\hline Albendazole & 80 & 70 & 61 & 84 & 75 & 65 \\
\hline
\end{tabular}

\subsection{In vitro antifungal activity of $A B Z$ and $L S N$ liquisolid formulation}

From the in vitro antifungal screening it was observed that all the compounds exhibited activity against all the organisms employed as indicated in (Table 10). Albendazole liquisolid formulation showed highest activity against Aspergillus Niger compared to pure albendazole. The antifungal activity was evaluated by measuring zones of inhibition area surrounding the formulations, larger the zone of inhibition (Figure 8 and Figure 9) indicates the more effective formulation. As Microtubules are important components of all eukaryotic cells [25]. They form the mitotic spindle for chromosome segregation. In many cells, they function in motility by forming cilia and flagella, and they also serve as major cytoskeletal elements. Microtubules are formed by the polymerization of cx- and 1- tubulin protein subunits. Several drug groups inhibit microtubule polymerization; however, the benzimidazoles and their liquisolid formulations are the most important of these in terms of their clinical applications [26-29].

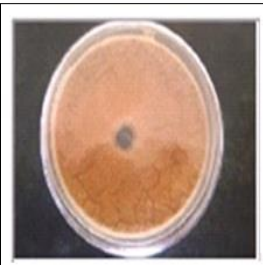

a.control

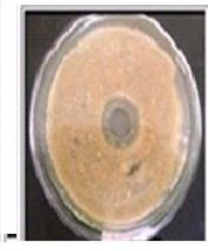

b. $A B Z 1 \mu \mathrm{g} / \mathrm{ml}=14.5 \mathrm{~mm} \quad$ c.ABZ3 $\mu \mathrm{g} / \mathrm{ml}=16.1 \mathrm{~mm}$

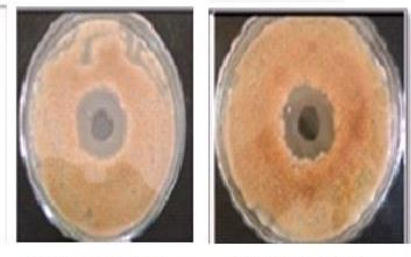

d.ABZ $5 \mu \mathrm{g} / \mathrm{ml}=20.3 \mathrm{~mm}$

Figure 8. Antifungal activity of pure albendazole with varying concentrations.

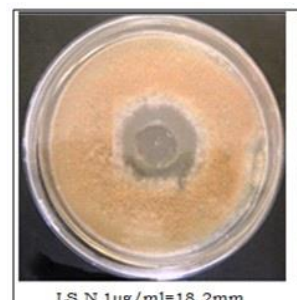

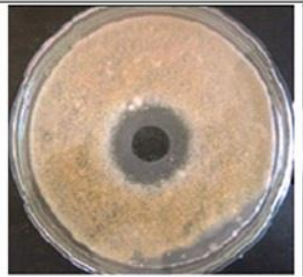

LS N $3 \mu \mathrm{g} / \mathrm{ml}=21.3 \mathrm{~mm}$

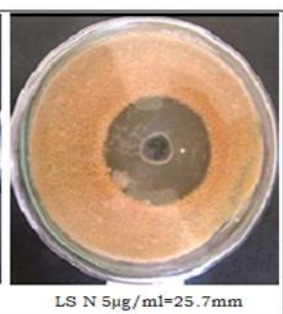

LS N $5 \mu \mathrm{g} / \mathrm{ml}=25.7 \mathrm{~mm}$

Figure 9. Antifungal activity of neusilin based ABZ liquisolid formulation against Aspergillus Niger at the conc. 1,3 and $5 \mu \mathrm{g} / \mathrm{ml}$ respectively. 
Table 10. Antifungal activity of albendazole neusilin based liquisolid formulations against Aspergillus niger.

\begin{tabular}{cccc}
\hline Formulation & \multicolumn{3}{c}{ Zone of Inhibition in (mm) } \\
\cline { 2 - 4 } & $1 \mu \mathrm{g} / \mathrm{ml}$ & $3 \mu \mathrm{g} / \mathrm{ml}$ & $5 \mu \mathrm{g} / \mathrm{ml}$ \\
\cline { 2 - 4 } Control & - & - & - \\
LS N & 18.2 & 21.3 & 25.7 \\
ABZ & 14.5 & 16.1 & 20.3 \\
\hline
\end{tabular}

\subsection{Stability study}

There were no significant changes in Drug content of all these formulations before and after storage at room temperature for period of 3 months. This shows that albendazole liquisolid formulations were stable at room temperature as shown in Table 11.

\section{CONCLUSION}

This study provided evidence that it is possible to load high amounts of drug into liquisolid compacts by replacement of the commonly used carrier materials by neusilin with high specific surface area and good flow and tableting properties allows considerably higher liquid adsorption capacities. Neusilin based tablets showed a remarkably improved dissolution rate in comparison with laboratory made tablets. The results showed that dissolution rate of the drug from liquisolid compacts were affected by changing the ratio of the carrier (neusilin) to coating material (aerosil). Moreover, with liquisolid compacts containing the drug suspended in PEG 400 the release rate increases with rising percentage of dissolved drug in the liquid portion. Among the liquisolid formulations showed potent and promising antifungal and anthelmintic activity compared to ABZ.

\section{MATERIALS AND METHODS}

Albendazole (Cipla Pharma PVT LTD, Mumbai), Neusilin (Abbott Health care PVT LTD. Research Park, Mumbai), Polyvinylpyrollidone, Polyethylene 400 (Loba chemie, Mumbai) Avicel 102 (Lupin, Pune) Aerosil 200, Crosscarmellose sodium (Meyer organics PVT.LTD Mumbai) all other reagents and chemicals were of analytical grade.

\subsection{Saturation solubility studies}

Solubility studies of ABZ were carried out in five different nonvolatile solvents, i.e. PEG 200, PEG 400, glycerin, polysorbate 80 and Polyethylene glycol (PG). Saturated solutions were prepared by adding excess drug to the vehicles and shaking on the shaker for $48 \mathrm{~h}$ at $25^{\circ} \mathrm{C}$ under constant vibration. After this period the solutions were filtered through a $0.45 \mu \mathrm{m}$ Millipore filter, diluted with $0.1 \mathrm{~N}$ HCL and analyzed by UV spectrophotometer at a wavelength of $291 \mathrm{~nm}$ against blank. Three determinations were carried out for each sample to calculate the solubility of ABZ.

\subsection{Determination of the angle of repose}

10 gms of powder excipient were weighed accurately and this powders carefully poured through the funnel until the apex of the conical pile so formed just reaches the tip of funnel. Maximum angle possible between the surface of the pile of the powder and the horizontal plane. This angle $\theta$ represents the angle of repose. It was taken as a measure for the flow characters of powders. An angle of repose corresponding to $33^{\circ}$ corresponded to optimal flow properties [30-31].

Table 11. Drug content of neusilin based liquisolid compacts.

\begin{tabular}{cc}
\hline Periods of storage & $\begin{array}{c}\text { Drug content (\%) of neusilin based liquisolid } \\
\text { compact formulation }\end{array}$ \\
\hline After 15 days & $98.43 \pm 0.32$ \\
After 1 month & $98.25 \pm 0.21$ \\
After 2 month & $97.85 \pm 0.25$ \\
After 3 month & $97.67 \pm 0.28$ \\
\hline
\end{tabular}




\subsection{Determination of flowable liquid retention potential ( $\Phi$-Value)}

To the ten gram $(10 \mathrm{gm})$ of powder excipient with increasing amounts of PEG 400 was added and mixed. The adsorbed PEG 400 results in a change in flow properties. At each concentration of PEG 400, the angle of repose for carrier and coating material were re-determined as stated above. The corresponding $\Phi$-value was calculated from the following equation,

$$
\Phi \text {-value }=\text { weight } \text { of liquid } / \text { weight of solid }
$$

The $\Phi$-values were plotted graphically against the corresponding angles of repose $\theta$. The Phi-value corresponding to an angle of repose of $33^{\circ}$, represented the flowable liquid retention potential ( $\Phi$-value) of powder excipients[30-32]

\subsection{Determination of liquid load factors (LF)}

The appropriate amounts of carrier and coating materials to produce acceptable flowing and compactable powders was calculated from the following equation,

$$
\mathrm{Lf}=\varnothing \mathrm{ca}+\varnothing \mathrm{co}(1 / \mathrm{R})
$$

Based on the physical properties of powders termed "flowable liquid-retention potential" (Ø-value). The maximum amount of liquid loads on the carrier material, termed "Liquid load factor" (Lf) [30-32]

\subsection{Precompression studies for prepared liquisolid systems}

Determination of angle of repose, Carr's index and Hausner's ratio were used to characterize flow properties of the liquisolid powder systems. The flowability of a powder was of critical importance in the production of pharmaceutical dosage forms in order to get a uniform feed as well as reproducible filling of tablet dies, otherwise, high dose variations will occur [33-34].

\subsection{Optimization of process variables by using $3^{2}$ factorial designs}

Liquisolid compacts were formulated by using the $3^{2}$ factorial designs. The two independent variables were selected for the present study was the drug concentration $\left(X_{1}\right)$ and Excipient ratio $\left(X_{2}\right)$. \% drug release rate i.e. dependent variable was evaluated. Three levels determined from preliminary studies of two variables were selected and nine possible batches were prepared. A polynomial equation was used to study the effect of variables on evaluation response of $\%$ drug release where the coefficients in the equation $\left(b_{0}, b_{1}, b_{2}, b_{12}\right)$ were related to the effects and interactions of the factors [35-40].

$$
Y=b_{0}+b_{1} X_{1}+b_{2} X_{2}+b_{12} X_{1} X_{2}
$$

Where, $b_{0}$ is the arithmetic mean response of nine batches, $b_{1}$ and $b_{2}$ coefficients of factor $X_{1}$ and $X_{2}$ and $\beta_{12}$ the coefficient of interaction of $X_{1}$ and $X_{2}$. The interaction $\left(X_{1} X_{2}\right)$ shows how the dependent variable changes when two or more factors are simultaneously changed. 'PCP Disso 2003 V3 software' was used to obtain values

\begin{tabular}{|c|c|c|}
\hline \multirow[b]{2}{*}{ Coded values } & \multicolumn{2}{|c|}{ Actual Values (mg) } \\
\hline & $\begin{array}{c}\mathrm{X}_{1} \\
\text { (Drug concentration) }\end{array}$ & $\begin{array}{c}\mathrm{X}_{2} \\
\text { (Excipient ratio) }\end{array}$ \\
\hline $\begin{array}{c}-1 \\
\text { (Low level) }\end{array}$ & 45 & 15 \\
\hline $\begin{array}{c}0 \\
\text { (Middle Level) }\end{array}$ & 50 & 20 \\
\hline $\begin{array}{c}+1 \\
\text { (High level) }\end{array}$ & 55 & 25 \\
\hline
\end{tabular}
of coefficients in the equation. The design is shown in Table 12.

Table 12. Three levels of factorial designs. 


\subsection{Preparation of neusilin based albendazole liquisolid compacts}

ABZ was dispersed in PEG 400 non volatile solvent to make 45, 50 and $55 \% \mathrm{w} / \mathrm{w}$ solutions (denoted as LS-1 to LS-9). Then a binary mixture of carrier and coating material contains neusilin as the carrier material and Aerosil-200 as the coating material at a ratio of 15:1, 20:1, and 25:1 was prepared. The binary mixture was added to the mixture containing the drug and vehicle under continuous mixing in a mortar. Different liquid loading factors were employed in liquisolid preparations. Therefore, different concentrations of neusilin and aerosil 200 were used to prepare different liquisolid formulations. $5 \% \mathrm{w} / \mathrm{w}$ of cross carmellose sodium as disintegrant was incorporated in an above powder blend and mixed for $10 \mathrm{~min}$. The final mixture was compacted on a $13 \mathrm{~mm}$ flat-faced punch and die set using a KBR Press (Type M- 15 Techno research instrument). The applied compression force was different from one formulation to another due to the variation in the tablet weight; however, sufficient compression force was used to attain acceptable tablet hardness important formulation characteristics of the prepared albendazole liquisolid formulations are shown in Table 13 [41-42].

\subsection{Preparation of directly compressed tablets of albendazole}

A conventional formulation of Albendazole $200 \mathrm{mg}$ (denoted as DCT) was directly compressed tablets. In addition, each Directly Compressible tablet contained $120 \mathrm{mg}$ Neusilin and $10 \mathrm{mg}$ Aerosil 200. In both formulation 5\% CCS as disintegrant. A tablet batch was mixed in mortar for $10 \mathrm{~min}$. The final admixture was compressed by using KBR press (techno research) sufficient compression force was used to attain acceptable tablet hardness.

\subsection{Post compression studies of liquisolid compacts}

Prepared compacts were subjected to evaluation of different properties including drug content uniformity, weight variation, tablet hardness, friability, tablet dimensions and disintegration.

\subsubsection{In vitro drug release}

Study In vitro dissolution study was carried out by using the USP II paddle apparatus. $900 \mathrm{ml} 0.1 \mathrm{~N} \mathrm{HCL}$ was used as dissolution media, at $50 \mathrm{rpm}$ and $37 \pm 0.5^{\circ} \mathrm{C}$. Appropriate aliquots are withdrawn at suitable time interval $(5,10,15,20,25,30,40,50,60 \mathrm{~min}$.) and filtered through whatman filter paper and diluted to $10 \mathrm{ml}$ with $0.1 \mathrm{~N} \mathrm{HCL} \mathrm{sink} \mathrm{conditions} \mathrm{was} \mathrm{maintained} \mathrm{throughout} \mathrm{the} \mathrm{study.} \mathrm{The} \mathrm{samples} \mathrm{ware} \mathrm{then} \mathrm{analyzed} \mathrm{at}$ $\lambda \max$ of $291 \mathrm{~nm}$ by UV/visible spectrophotometer after suitable dilutions [43].

\subsubsection{Differential scanning calorimetry (DSC)}

DSC was performed in order to assess the thermotropic properties and thermal behavior of the drug (ABZ) and the prepared liquisolid compact. About $5 \mathrm{mg}$ of the sample are sealed in the aluminum pans and heated at the rate of $10^{\circ} \mathrm{C} / \mathrm{min}$, covering a temperature range of $40^{\circ} \mathrm{C}$ to $300^{\circ} \mathrm{C}$ under nitrogen atmosphere of flow rate $100 \mathrm{ml} / \mathrm{min}$.

\subsubsection{Powder X-Ray diffraction (P-XRD)}

For characterization of crystalline state, the X-ray diffraction (XRD) patterns for albendazole and the Prepared liquisolid compact was determined using X-ray diffractometer with a copper target, (PW 3710 BASED) using Ni filtered Cuk (a) radiations, a voltage of $35 \mathrm{kv}$, current of $30 \mathrm{~mA}$ and receiving slit of $0.2 \mathrm{In}$. Samples were analyzed over $2 \theta$ range of $10-70^{\circ}$.

\subsection{Anthelmintic activity of albendazole liquisolid compact against adult indian earthworm pheritima posthuma}

Indian adult earthworms (pheretimaposthuma) were used to study anthelmintic activity. The earthworms (collected from the water logged areas of soils, Karad) were washed with normal saline to remove all fecal materials. The earthworms selected were $4-5 \mathrm{~cm}$. in length and $0.1-0.2 \mathrm{~cm}$ in width were used for all experimental protocol. The earthworm resembles both anatomically and physiologically to the intestinal roundworm parasites of human beings, hence can be used to study anthelmintic activity $(n=3)$.

Group 1: Treated with $2 \% \mathrm{v} / \mathrm{v}$ Tween 80 in normal saline and kept as a control

Group 2: Treated with albendazole at concentration of $20 \mathrm{mg} / \mathrm{ml}$

Group 3: Treated with 5, 10 and $20 \mathrm{mg} / \mathrm{ml}$ in $2 \% \mathrm{v} / \mathrm{v}$ Tween 80 in normal saline concentrations 
Table 13. Formulation of neusilin based ABZ liquisolid compacts.

\begin{tabular}{|c|c|c|c|c|c|c|c|}
\hline $\begin{array}{l}\text { Liquisolid } \\
\text { Compacts }\end{array}$ & $\begin{array}{c}\mathrm{D} / \mathrm{C} \\
(\% \mathrm{w} / \mathrm{w})\end{array}$ & $\begin{array}{c}\mathrm{R} \\
\text { (Excipient } \\
\text { Ratio) }\end{array}$ & $\overline{\mathrm{Lf}}$ & $\begin{array}{c}\text { Liquid } \\
\text { vehicle(mg) }\end{array}$ & Carrier Q (mg) & $\begin{array}{l}\text { Coating } \\
\text { q (mg) }\end{array}$ & $\begin{array}{l}\text { Unit } \\
\text { dose } \\
(\mathrm{mg})\end{array}$ \\
\hline LS N -1 & 45 & 15 & 1.61 & 244.44 & 151.82 & 10.12 & 628.29 \\
\hline LS N -2 & 50 & 15 & 1.61 & 200 & 124.22 & 8.28 & 560.52 \\
\hline LS N- 3 & 55 & 15 & 1.61 & 163.63 & 101.63 & 6.77 & 496.87 \\
\hline LS N - 4 & 45 & 20 & 1.57 & 244.44 & 155.69 & 7.78 & 639.90 \\
\hline LS N -5 & 50 & 20 & 1.57 & 200 & 127.69 & 6.369 & 561.84 \\
\hline LS N-6 & 55 & 20 & 1.57 & 163.63 & 104.22 & 5.211 & 497.95 \\
\hline LS N -7 & 45 & 25 & 1.55 & 244.44 & 157.70 & 6.30 & 640.46 \\
\hline LS N -8 & 50 & 25 & 1.55 & 200 & 136.05 & 5.16 & 562.30 \\
\hline LS N-9 & 55 & 25 & 1.55 & 163.63 & 105.56 & 4.00 & 498.32 \\
\hline
\end{tabular}

Observed for their spontaneous motility and evoked responses and recorded the time taken for worms to become motionless was noted as paralysis time and to ascertain death, each worm was frequently applied with external stimuli which stimulates and induce movement in the earthworms, if alive [30-33].

\subsection{Antifungal activity}

The in vitro antifungal activity of liquisolid compact formulations at different concentrations $(1,3$ and 5 $\mu \mathrm{g} / \mathrm{ml}$ ) and control was pure solvent (DMSO) against fungal species Aspergillus niger. By using cup-plate method [26-28].

\subsection{Stability study}

The stability studies of formulated formulation were carried out at room temperature for a period of 15 days, 1, 2 and 3 months. After this period, the stored compacts were evaluated for drug content.

Acknowledgements: Authors are thankful to Management of Krishna Institute of pharmacy of KIMSDTU, Karad for providing the facilities to carrying out this research work and Head of common facility center of Shivaji University of Kolhapur for providing DSC and X-RPD facility.

Author contributions: Concept -A.S., A.S.; Design - A.S, A.Y; Supervision - R.D., A.Y.; Materials - A.S.; Data Collection and/or Processing - A.S, A.S; Analysis and/or Interpretation - A.S., A.S., S.S.; Literature Search - A.S., A.S., SS; Writing - A.S, S.S; Critical Reviews - A..S., A.Y., R.D, S.S., A.S.

Conflict of interest statement: We wish to confirm that there are no known conflicts of interest associated with this publication and there has been no significant financial support for this work that could have influenced its outcome.

\section{REFERENCES}

[1] Vaskula S, Vemula S, Bontha V, Garrepally P.Liquisolid compacts: an approach to enhance the dissolution rate of nimesulide. J Appl Pharm Sci. 2012; 02: 115-121. [CrossRef]

[2] Dressman JB, Reppas C. In vitro-in vivo correlations for lipophilic, poorly water-soluble drugs. Eur J Pharm Sci. 2000; 11: S73-S80. [CrossRef]

[3] Venkateswarlu K, Preethi JK, Chandrasekhar KB. Enhancement of loperamide dissolution rate by liquisolid compact technique. Adv Pharm Bull. 2016; 6: 385-390. [CrossRef]

[4] Dias R, Mali K, Ghorpade V, Havaldar V, Mohite V. Formulation and evaluation of carbamazepine liquisolid compacts using novel carriers. Ind J Pharm Sci. 2017; 51: S69-S78. [CrossRef]

[5] Javadzadeh Y, Jafari-Navimipour B, Nokhodchi A. Liquisolid technique for dissolution rate enhancement of a high dose water-insoluble drug (carbamazepine). Int J Pharm. 2007; 341:26-34. [CrossRef]

[6] Indian Pharmacopoeia government of India, Ministry of Health and Family Welfare. Delhi: India .2007 
[7] Ibrahim MA, Al-Anazi KF. Enhancement of the dissolution of albendazole from pellets using mtr technique. Saudi Pharm J. 2013; 212:15-223. [CrossRef]

[8] Priotti J, Codina AV, Leonardi D, Vasconi MD, Hinrichsen LI, Lamas MC. Albendazole microcrystal formulations based on chitosan and cellulose derivatives: physicochemical characterization and in vitro parasiticidal activity in trichinellaspiralis adult worms. AAPS Pharm Sci Tech. 2017; 18(4):947-956. [CrossRef]

[9] Hengsawas SS, Keen JM, Huang S, Zhang F, McGinity JW, Williams RO, Hot melt extrusion versus spray drying: hot melt extrusion degrades albendazole. Drug Dev Ind Pharm. 2017; 43(5):797-811. [CrossRef]

[10] Kr V, Yalavarthi PR, Vadlamudi HC, Kalluri JKY, Rasheed A. Process, Physicochemical Characterization and In-Vitro Assessment of Albendazole Microcrystals. Adv Pharm Bull. 2017; 7(3):419-425. [CrossRef]

[11] Chattah AK, Pfund LY, Zoppi A, Longhi MR, Garnero C. Toward novel antiparasitic formulations: Complexes of Albendazoledesmotropes and $\beta$-cyclodextrin. Carbohydr Polym. 2017; 164(15):379-385. [CrossRef]

[12] Ghanbarzadeh S, Khalili A, Jouyban A, Emami S, Javadzadeh Y, Solhi M, Hamishehkar H. Dramatic improvement in dissolution rate of albendazole by a simple, one-step, industrially scalable technique. Res Pharm Sci. 2016; 11(6):435444. [CrossRef]

[13] Bongioanni A, Araújo BS, de Oliveira YS, Longhi MR, Ayala A, Garnero C. Improving Properties of AlbendazoleDesmotropes by Supramolecular Systems with Maltodextrin and Glutamic Acid. AAPS Pharm Sci Tech. 2018; 19(3):1468-1476. [CrossRef]

[14] Pacheco PA, Rodrigues LNC, Ferreira JFS, Gomes ACP, Veríssimo CJ, Louvandini H, Costa RLD, Katiki LM. Inclusion complex and nanoclusters of cyclodextrin to increase the solubility and efficacy of albendazole. Parasitol Res. 2018; 117(3):705-712. [CrossRef]

[15] MarrinerS, Morris D, Dickson B. Pharmacokinetics of albendazole in man. Eur J Clin Pharm. 1986;30:705-708. [CrossRef]

[16] VadherAH,.Parikh JR, Parikh RH, Solanki AB. Preparation and characterization of co-grinded mixtures of aceclofenac and neusilin us2 for dissolution enhancement of aceclofenac. AAPS Pharm Sci Tech. 2009; 10:606-614. [CrossRef]

[17] Elkordy AA, Tan XN, Essa EA. Spironolactone release from liquisolid formulations prepared with Capryol ${ }^{\mathrm{TM}} 90$ Solutol- HS-15 and Kollicoat- SR 30 D as non-volatile liquid vehicles. Eur J Pharm Biopharm. 2013; 83: $203-223$. [CrossRef]

[18] Ngiik T, Elkordy AA, Effects of liquisolid formulations on dissolution of naproxen Eur J Pharm Biopharm. 2009; 73: 373-384. [CrossRef]

[19] Hentzschel CM. Optimization of the liquisolid technology - identification of highly effective tableting excipients for liquid adsorption. Dissertation. 2011:1-119.

[20] Karmarkar AB. Effect of Ceolus KG-802 on the dissolution rate of fenofibrate liquisolid tablets: Preformulation and formulation development studies. Drug Discov Ther. 2010; 4: 493-498.

[21] Basu B, Bagadiya A, Makwana S, Vipul V, Batt D. Formulation and evaluation of fast dissolving tablets of cinnarizine using superdisintegrant blends and subliming material. Adv Pharm Technol Res. 2011; 22:66-273. [CrossRef]

[22] Bastos M, Friedrich R, Beck R.Effects of filler-binders and lubricants on physicochemical properties of tablets obtained by direct compression: A 22 factorial design. Lat Am J Pharm. 2008; 27:578-583.

[23] Shirsand S, Suresh S, Kusumdevi V, Swamy P. Formulation design and optimization of fast dissolving clonazepam tablets by sublimation method. Ind J Pharm Sci. 2011; 73:491-496. [CrossRef]

[24] Ikechukwuogu G. In vitro anthelmintic potentials of Bambusa vulgaris (1.) leaf extracts using adult african earthworm (eudriluseugeniae) from southern nigeria. IJNDD. 2012; 4: 306-310.

[25] Denyer P, Hodges NA, Gorman SP. Hugo and Russell's pharmaceutical microbiology. 7th ed. Blackwell Science Publishing Company. Oxford, UK 2004.

[26] Kokare CR. Pharmaceutical microbiology experiments and techniques. 1st ed. Career Publications, Nashik 2005.

[27] Gaud RS. Gupta GD. Practical.Microbiblogy. 7th ed. Nirali Prakashn Pune 2004.

[28] Anupa S, Surinder G, Birendra S, Goyal S. In vitro antifungal evaluation of albendazole solid dispersion. AJBPS. 2011; 4: $164-148$. 
[29] Khalaf R, Jabir H, Abbas F. Investigation of the antifungal activity of some non-antifungal drugs in clinical isolates of otomycosis: In vitro study. J Thi-Qar Sci. 2012; 3 (2):31-39. [CrossRef]

[30] Wells J. Pharmaceutical Preformulation: The physicochemical properties of drug substances, In: Aulton M. pharmaceutics: The science of dosage form design, 2nd ed. Churchill Livingstone, Longman Group, Edinburgh, 2002, pp. 114-138.

[31] Ngiik T, Elkordy AA. Effects of liquisolid formulations on dissolution of naproxen. Eur J Pharm Biopharm. 2009; 73: 373-384. [CrossRef]

[32] Elkordy AA, Tan XN, Essa EA. Spironolactone release from liquisolid formulations prepared with Capryol ${ }^{\mathrm{TM}} 90$ Solutol- HS-15 and Kollicoat- SR 30 D as non-volatile liquid vehicles. Eur J Pharm Biopharm. 2013; 83: 203-223. [CrossRef]

[33] Lachman L. Liberman HA, Kanig JL. The theory and practice of industrial pharmacy. 3rd ed. Varghese publication house, Mumbai 2008.

[34] Banker GS, Anderson NR. Tablets, In: Lachman L. Lieberman HA, Kanig JL, The theory and practice of industrial pharmacy, 3rd ed. Varghese publishing house, Bombay 2008.

[35] Lundstedt T, Seifert E, Abramo L, Thelin B, Nystrom A, Pettersena J, Bergman R. Experimental design and optimization. Chemom Intell Lab Syst. 1998; 42: 30-40. [CrossRef]

[36] Kerly FM, Pasqualoto RF, Guterres TM, Pereira FS, Ferreira MC. A study of physicochemical and biopharmaceutical properties of Amoxicillin tablets using full factorial design and PCA biplot. Analytica Chimica Acta. 2007; 595:216220. [CrossRef]

[37] Late S, Yi-Ying Y, Banga A. Effects of disintegration-promoting agent, lubricants and moisture treatment on optimized fast disintegrating tablets. Int J Pharm. 2009; 365:4-11. [CrossRef]

[38] Shirsand S, Suresh S, Kusumdevi V, Swamy P. Formulation design and optimization of fast dissolving clonazepam tablets by sublimation method. Ind J Pharm Sci. 2011; 73:491-496. [CrossRef]

[39] Basu B, Bagadiya A, Makwana S, Vipul V, Batt D. Formulation and evaluation of fast dissolving tablets of cinnarizine using superdisintegrant blends and subliming material. Adv Pharm Technol Res. 2011; 22:66-273. [CrossRef]

[40] Jishnu V, Prabhakaran R, Gilhotra R. Formulation and evaluation of cephalexin extended release matrix tablets using 32 factorial design. J Young Pharm. 2011; 3:259-266. [CrossRef]

[41] Saadia VB, Tayel A, Iman I, Dina Louis S. Improvement of dissolution properties of Carbamazepine through application of the liquisolid tablet technique. Eur J Pharm Biopharm. 2008; 69:342-347. [CrossRef]

[42] United States Pharmacopeia-National Formulary. 2007; 1092-1145.

[43] Yadav P, Sing HR. A review on anthelmintic drugs and their future scope. Int J Pharm Pharm Sci. 2011; 3: 1721.

This is an open access article which is publicly available on our journal's website under Institutional Repository at http://dspace.marmara.edu.tr. 